\title{
An Appropriate Cloud Computing Business Model and Its Services for Developing Countries: A Comparison of Cloud Computing Business Model in Indonesia
}

\author{
Roland Tumbelaka Palar \\ Faculty of Information Technology \\ Satya Wacana Christian University \\ Jl. Diponegoro 52-60, Salatiga
}

\author{
Danny Manongga \\ Faculty of Information Technology \\ Satya Wacana Christian University \\ Jl. Diponegoro 52-60, Salatiga
}

\author{
Wiranto $\mathrm{H}$. Utomo \\ Faculty of Information Technology \\ Satya Wacana Christian University \\ Jl. Diponegoro 52-60, Salatiga
}

\begin{abstract}
This paper examined the business models of cloud computing and its services that appropriate with custumers needs in developing countries especially in Indonesia. The research was carried out through comparative analysis processes of the types of services that were offered by the cloud computing providers in Indonesia. It included the cloud computing providers from abroad which have customers in Indonesia. The expected results of this study were to get the information about cloud services in Indonesia (the cloud provider customers are from Indonesia) and to find out the most popular cloud services in developing countries, especially Indonesia.
\end{abstract}

\section{Keywords}

Cloud computing, Business Model, Developing Countries.

\section{INTRODUCTION}

Indonesia as a developing country is quite interesting to be discussed especially about the technology development. Then, every developing country has their individual stories. The developing countries have different development and growth in their technology. There are some factors that influence the development of technology; one of the factors is the social culture and habits. The utilization of technology in developed countries is a common thing to find. But how about the condition of the developing country like Indonesia?

The development of technology that has been discussed nowadays is about the cloud computing. This issue about cloud computing that was mentioned before can help the world of industry and company become easier to build the infrastructure of computerization efficiently and establish the higher step of scalabilities. It makes those businessmen interested to gain more information about, learn, and use it. Now, to get more information about the service and the business model for cloud computing suitable for the developing countries like Indonesia, including that has been presented in Indonesia, it should be seen and analyzed deeper so that all information that can be compiled is complete.

The presence of cloud computing that changes the previous habit in using technology is affected by the innovation of the other aspects of technology. The one which got the induced is the innovation to the model of business. According to IBM who is the senior provider in the technology computing, said that this kind of innovation will bring the influence in creating the new market share and it is different from the other innovation. To join actively in this new market competition, those providers are demanded to use or even be able to create the business model related to the need by still considering the condition of each country.

Based on that background, we assume that it can cause emerge of bussines model variety so that the implementation will become various for each provider. To see the compatibility of the business model with the status of developing country, it is important to do the comparison of how much the compatibility business model with the condition of a country in its development and growth. Overall, this research will compare the background knowledge that has been mentioned before.

\section{CLOUD COMPUTING}

Before we go any further to the comparison, it is useful to define what cloud computing is. Cloud computing is a part of current technological advances, specifically as a part of technology in internet working. Judith et.al., defines "cloud" as an overall process of computing through computing infrastructure. That includes the applications, business processes, up to personal collaboration that can be accessed wherever and whenever, as the computing services and its infrastructure are very accessible [1]. Cloud computing for some people is considered as an art technique that provides a flexible IT infrastructure that integrates high scalability and multi-tenancy as its supporting features [12]. Cloud computing are classified into three basic forms, namely (1) Public Cloud, (2) Private Cloud, and (3) Hybrid Cloud in which the latter is a combination of public and private cloud. The definition of cloud computing has been clearly defined by NIST (U.S. National Institute of Standard and Technology) as a model constructed from the needs and demands, access to network and computing resources (e.g. network, server, media storage, applications, and services) which were expected to be fast and easily access with minimum supervision and interaction with service providers [2].

Cloud computing is also referred to a set of network services which provide scalability, guarantee for personal quality services with reasonable infrastructure built to meet necessities which are easily and widely accessible [3]. In term of centralized data, virtualization technology takes an important role as a resource in cloud computing infrastructure. Through this virtualization, cloud supports the application of the concept of grid [4]. Should formerly we understand that the concept of grid computing is decentralized data which is paradoxical with the nature of cloud. Yet, cloud modifies the concept with the use of virtualization technology.

Since cloud computing utilizes virtualization as its resource, then data storing will be done through this virtualization as 
well. Given observant safety, the subsequent storage process will be used to store software that later will be utilized or rented as a cloud service [5]

\subsection{Elements Forming of Cloud Computing Services}

In supporting and developing main services, including the variations that provides by the cloud provider, here are shown some elements that are important as a building infrastructure and cloud computing services.

\section{- Web Services}

Cloud computing service is a service that is mostly made up from a set of web services that are managed in a Service Oriented Architecture (SOA) [16], where the services are defined to give the standard business functionality. The use of web service has a special reason, which is to create a standard where the web service actively functions in giving the entity of information on different platforms [17]. In the SaaS model, applications which are rent can be built from the same service composition or different account providers. The services can be reused and combined to other business applications. Take for example, the popular models of API (Application Programmable Interface) such as Google Maps, YouTube, Flicker and others, when combined in an application, will result in applications that are interesting and applicable [15]

\section{- Hardware Virtualization}

The problem that appears in the data center which has large scale (large-scale data center), where the data center handles the data users and becomes host to variety of applications, mostly occurs in the operational and maintenance process. Commonly, data centers consist of hundreds or thousands of computers with specifications that may be different from each other so that it will make different problems. It causes difficulties in the maintenance process and takes longer time to repair the damage or to find solutions for the problems occur [15]. As a solution, virtualization in resource data center, such as virtualization processors, memory and $\mathrm{I} / \mathrm{O}$ devices is seen as an interesting idea and suitable for the dynamic data center [18], as required in the cloud computing service, in which the flexibility and scalability is the main factor.

\section{- $\quad$ Autonomic Computing}

Along with the increasing complexity of computing systems, autonomic computing provides improvements to the system by reducing human involvement in the operating system, or with the understanding that the system automatically manages itself, but still under the instructions and guidance from human as the brainware [19]. Based on a survey result, IBM Autonomic Computing Initiative has contributed in 4 (four) properties from Autonomic System (1) self-configuration, (2) self-optimization, (3) self-healing, and (4) self-protection. Furthermore, IBM also proposes a reference model for autonomic control loops from autonomic managers which are referred to MAPE-K (Monitor Analyze Execute Plan-Knowledge) [19, 20].

\subsection{The Advantages of Cloud Computing Services Utilization}

An application performed different from its conventional way on a business activity is always motivated by several strong reasons. One of them is the lure of the increasing profits through the optimization and efficiency in using the resources. Small and medium companies are identified as potential users of cloud services, which expect to get some advantage points such as [11].

- Cost

The use of virtualization in cloud services causes the allocation cost to move from fixed cost to variable cost and the expenses of excessive energy usage in data center infrastructure becomes no longer exist, so that the saving of energy from utilizing the resources is achieved [9]. The efficiency cost because of the reducing expenses also leads to the reducing main capital of the company [10].

- Business Continuity

The availability of regular maintenance services, data backup and redundancy of data by the cloud provider ensure the stability of the business continuity [11].

- $\quad$ Flexibility

Flexibility is available through the scalability of computing and access that can be dynamically adjusted to the needs of the company [9].

\section{- Opportunity}

The company's opportunities and chances to focus on things other than the focus on technology and IT management is now more widely open. The complexity and changing technology of IT for the business needs of customers, which are increasing and various and must be faced by the company, are decreasing by the presence of cloud services that are available and able to collaborate with the features and services offered by the company [9].

\section{BUSINESS MODEL}

Business model discusses about how an organization can create, contribute, and capture valuable opportunities through a rational way. Rational manner used by cloud computing provider in making profits is by providing services which can be categorized into three categories [1];

\section{Infrastructure as a Service (IaaS)}

The intended service in this category is rental hardware, such as server, network technology, media storage, and so on, which include in virtualization technology for managing resources. Service payments are based on the use of the service (time, bandwidth, transaction, storage, etc.) [7]. IaaS functions as the lowest layer that brings basic infrastructure support service [12]. Infrastructure leased by cloud provider is dynamic, in which the infrastructure may be both enlarged and reduced depending on the customer's needs. The example of IaaS is Amazon EC2 (Amazon's Elastic Compute Cloud).

\section{Software as a Service (SaaS)}

This category offers services in term of business application stored in the server cloud computing, for example CRM (Customer Relationship Manager). In Saas, services are divided into two types, namely (1) simple-form of multi-tenancy providing a separate resource for each user, and (2) the fine grain of multitenancy in which the users share resources, in this care storage media, server, and the like. However, the data and access are separated for each user. SaaS is built as a topmost later which offers a complete application as service on demand [13]. 


\section{Platform as a Service}

In the third category, we can see the evolution of the common web service hosting. Evolution lies on the service provided by cloud provider that gives an ease to determine which software developers environment would be solely suitable with the purpose of building application development. If the current web hosting has set specification at the beginning of subscription, developers should adjust themselves to this very condition, then it is quite different from Paas, as specifications are not set at the beginning, rather they can be determined based on the application developer request. By doing this procedure, an ideal state to develop and build applications required can be reached.

PaaS is put in the middle of cloud computing services between IaaS and SaaS. It offers platforms oriented services and provides environment for hosting user's application and user custom services [12].

Besides the three abovementioned services business models, if we trace back to the definition of cloud computing by NIST, then the four categories of cloud service deployment model will be found to be combined with the first three categories of cloud services previously mentioned, they are (1) private cloud to be exclusively used by single organization, (2) public cloud to be freely accessed by public, (3)community cloud to be shared with other organizations, and (4) hybrid cloud, which is the combination of private, public, and community cloud [2].

Private cloud is recognized as a deployment model to provide internal data center of a business that is not available for public access [14]. Private cloud also mentioned as a highly virtualized cloud space which is dedicated to a specific company. It is designed to handle company workloads and provides a specific function coming from company's needs [1].

If private cloud access is closed for public access, then public cloud is open to anyone. It provides applications and services that are standardized by its provider and used by lots of people [1]. If a company concerned about data privacy, this kind of deployment model might not be a right choice. Public cloud is more suitable for collaboration projects.

Beside private and public cloud, there is hybrid cloud that tries to cover cloud customers needs in making online environment and services that are accessed by lots of people but still can keep the private data and its application costumed by the company [1].

Having a similar implementation with public cloud but a little bit different concept, community cloud is built based on concerns in same mission, requirement, policy and compliance consideration, and needs to be shared, to several organization or to support a specific community [1]. As an example of community cloud is OpenCirrus that is well formed by several companies like Intel, HP, Yahoo and others

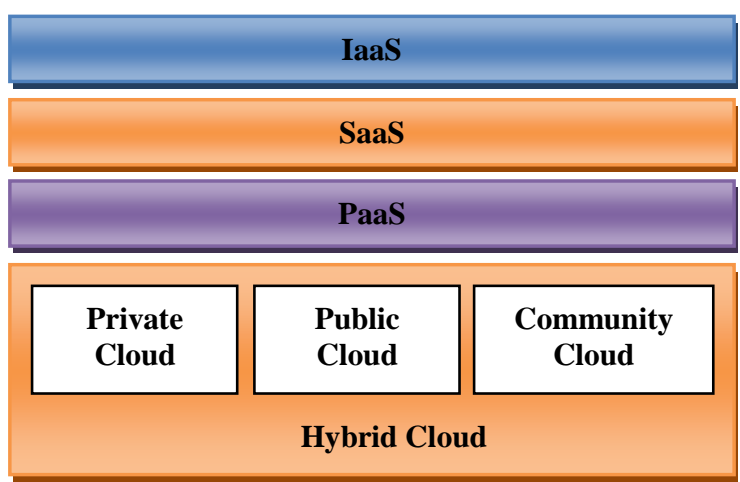

Figure 1. Cloud computing deployment and service models

\section{RESEARCH PURPOSE}

The aims of this research are mentioned below.

1. To compare the business model of cloud computing which has been presented in Indonesia.

2. To value the business model which is found by seeing the compatibility and the appliance of the business model with Indonesia's condition as a developing country, with the assessment indicator that has been decided and assumed to represent the condition of Indonesia as a developing country.

The result of the research is expected to give some benefits as mentioned below.

1. The result can be one of suggestions to develop the new business model or to modify on the business model that has existed to be more adaptive to the needs of the developing country.

2. The result of this research can be used as a reference to next researches about the business model of cloud computing.

\section{RESEARCH CONTRIBUTION}

Contributions given through this research are the process of comparing the business cloud computing that is released in Indonesia as a proof that the cloud computing service provider tries to make a variety of services through a variety of business models that used to be able to fill consumers' needs and able to adapt with the conditions of Indonesia as a developing country. Through this research, the government as a stakeholder in the development and growth of cloud computing in Indonesia becomes more aware with what need to be prepared along with the readiness of the infrastructure to support the presence of new technologies like cloud computing. It can also trigger the new formation from business opportunities and preserve the stability of state which is conducive to investment climate.

It is aimed for Indonesian in the future to be better prepared to accept the new technology ideas that can improve the quality of life and convenience for the citizens.

\section{RELATED WORK}

Here, is an overview from several studies that are related to this research. [8] Victor Chang, Gary Wills and David De Roure presented the Business Cloud Cube Model (CCM) and Hexagon which are used to classify the cloud computing business model in 8 (eight) categories. They are also to 
compare the differences shown in the eight (8) business model and make the model as a guide to operate the business model in which the cloud should have to focus on business model. The purpose from both models, CCM and Hexagon models, which have been presented, is to give the best solutions for the formation of cloud business models that are appropriate for business needs. According to Victor et al, the use of CCM and Hexagon are divided into 8 business models as follow.

\subsection{Service provider and Service Orientation}

Service provider and Service Orientation are public services which are provided by public cloud services that include infrastructure, platform and software as a service. Consumers in this business model are usually used by public cloud services as outsourcing. The weaknesses in this business model are on the competition between infrastructure services, platform and software offered to consumers.

\subsection{Supports and Service Contracts}

This business model uses the solution principles of private ownership of the domain and services, including infrastructure, platform and software services. The weaknesses from this business are seen when the time of the contract expires while it has not been decided to extend the contract yet. As the result, this period will make the service disconnected for a while.

\subsection{In House Private Clouds}

This business model just handle the need of private cloud so, the services are not outsourced. This business model is usually applied to SaaS service model. The weakness from this business model is that it cannot give insurance for data security and are not suitable to handle complex projects.

\subsection{All in One Enterprise Cloud}

This model is a combination of Service Provider, Orientation Model and In-House Private Cloud. Cloud business model is more suitable for large companies. The business model is able to consolidate the different business activities in which this model can handle the SaaS ecosystem approach or be comprehensive. As a weakness, the model is not suitable for small and medium sized businesses.

\subsection{One Stop Resources and Services}

This business model has the similar characteristics between Service Provider and Orientation Model, but often the combination with services which are out sourced and inhoused. This model is suitable to be applied in academic and business environments that require collaboration or cooperation. This collaboration will also give benefits for both things. The drawback from this model occurs when the members of the community, organization or one of the collaborating groups do not give the contribution.

\subsection{Government Funding}

This business model has outsourcing characteristic and the application is provided by the government.

\subsection{Venture Capitals}

Venture Capitals are the business model which is similar to Government model approach. It is suitable for an organization that lacks of funding in building cloud infrastructures.

\subsection{Entertainment and Social Networking.}

This business model focuses on SaaS services. A characteristic of this model is a large number of users which increases the service, advertising and sales. Users on this model can instantaneously and quickly become popular to get profit if they successfully implemented this business model. The weakness from this model is on the user's behavior that is affected by the entertainment and enjoyment for life relationships in this business model.

\section{CLOUD COMPUTING IN INDONESIA}

As a developing country, Indonesian business people are implementing various methods and technologies for adoption by various purposes. It also includes cloud computing which participates on development program in this country. Surely, the developing countries are still unconsidered to find the right method to achieve successfulness in bringing the country into a developed country in all areas, especially technology. In the role of cloud computing for developing countries like Indonesia, cloud computing providers are required to meet business needs. Ranging from small businesses to enterprisescale should be on the cover in the cloud computing service.

Since the business of cloud computing are widely open, the providers are competing to get the profit in this new business. One day, they would realize that this little organization will grow and their needs become increase with the conditions in developing countries, that have unstable economic level, not only make a profit for the organizations but also suffer if they do not readily respond when business environment is changing in economic problems. Here, to accommodate the dynamic needs, cloud computing is supposed to be a solution. As a developing country that has not had the proper orientation yet, the cloud providers try to use their own methods to meet the expectations from the organization or business people who need their services. This makes the diversity of emerging services and new business phenomenon based on cutting-edge technology resulting from the dynamic range requirements. Nevertheless, behind this competition, the infrastructure of telecommunications and national stability is unconsidered for the implementation of cloud computing in Indonesia. Certainly, it becomes a challenge for the cloud computing providers to remain present to give the best service for customers in Indonesia.

\section{CLOUD COMPUTING PROVIDER IN INDONESIA}

From these results, it was found several cloud computing providers who are actively competing in offering its services to meet the needs of the organization and for the dynamic business in Indonesia. Those providers are written on the following paragraphs.

\subsection{Telkom Cloud}

PT. Telkom Indonesia cooperates with Microsoft to provide computing service and it based on cloud computing through Telkom cloud. This service is called Virtual Private Server (VPS). VPS service offered is a service that helps customers to have virtual server where customers can install application, do some partition, do the reboot just like played as a dedicated server based on the customers' need and it can be held by the collaboration between PT Telkom as the biggest telecommunication company in Indonesia and one of the 
biggest software providers in the world, Microsoft. Then, the business infrastructure in this service is shown in the figure 2 .

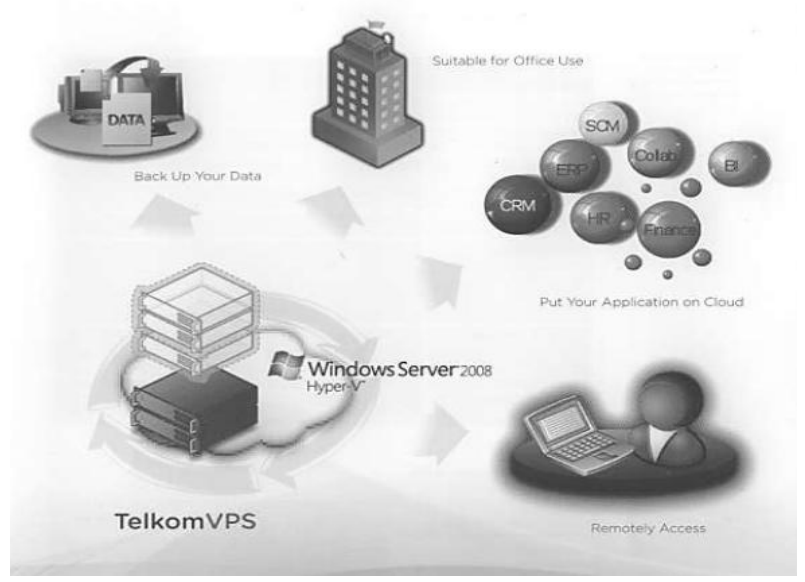

Figure 2. Business Infrastructure of Telkom Cloud

The target from Telkom Cloud product is for the customers who have cooperated company and small medium business.

\subsection{Indonesian Cloud}

PT Indonesia Cloud, located in Jakarta, offers different cloud service from Telkom Cloud. The cloud service which is established by PT Indonesian Cloud operates for facilitating the research and developing the cloud computing innovation. Recently, PT Indonesian Cloud cooperates with Institute Technology Bandung (ITB), one of famous universities in Indonesia, by giving facilities for cloud computing for organizations, for example ITB, in that both of them rely and give profit to each other.

ITB does some research related to the content, computerization system, communication system and the integration which is facilitated by PT Indonesian Cloud and its theme are about cloud computing. The results of this research will be used as a suggestion and idea to develop the cloud computing service in one side of Indonesia Cloud. It is important to know that Indonesian Cloud also provides the cloud service for Usaha Kecil Menengah (UKM) and Koperasi through information management service based on cloud computing. This service helps UKM to rent the ICT service without spending lots of money for infrastructure, the manageability, and platform even the other IT application services.

Indonesian Cloud's solution is expected to give the recent and actual information online for Koperasi and UKM about the performance of the business and accountant.

\subsection{PT Infinys System Indonesia}

The solution from cloud computing provider is the result of the cooperation between Microsoft and PT Infinys System Indonesia, which is one of Microsoft Gold Partner in Indonesia. The cloud computing service which is offered by this company is based on Software as a Service (SaaS). PT Infinys System services their customers through the rent of cloud server hosting to place the customers' application. The profit of this service makes the customers feel secure and be free from the process of the maintenance and monitoring their application.

\subsection{DynaLabs Cloud}

The collaboration between MorphLabs and PT Pratesis as the legal distributor in Indonesia present the cloud service which is called as DynaLabs Clouds. DynaLabs cloud is a virtual private cloud service which is similar to the Telkom Cloud service. The concept of DynaLabs Cloud service offers solution for hardware cloud.

\subsection{Huawei Cloud}

Cloud services by Huawei that will be presented later in Indonesia has different target user from the cloud providers that is mentioned before. Here, core business lies in the mobile phone and other mobile devices through via Cloud ${ }^{+}$. Later, Huawei is trying to give different breakthrough which is expected to be a trend.

Here, the use of mobile phones is quite a lot in Indonesia, Huawei sees the business opportunities more open and it is promising to make a profit through the cloud services that will be presented. Huawei's cloud computing services are divided into two kinds, (1) cloud data center that provides combined services to the needs of IaaS and PaaS distribution, network formation, smart monitoring and transparency (openness). Then, (2) cloud application solutions that convert traditional communication services such as SMS, MMS, etc become a cloud-based computing. Besides the traditional services, supports for cloud supporting services are to handle network management system, system OSS, BSS system and IDC cloud until desktop cloud is also available.

Instantly, with some of the additional services provide by Huawei, it is not only struggling in the field of mobile telecommunications alone but also venturing into the IT field.

\subsection{HP Cloud Computing Solution}

In 1947, Hewlett Packard was known as the experienced player in the field of information technology. It is common to the Indonesian community which certainly did not want to get left behind from the movement of new players in the field of IT. HP has a service cloud computing solutions which are already prepared to be presented in Indonesia. Moreover, Hybrid HP Delivery, which offers a Hybrid private and HP Cloud System that supports the HP cloud maps where system, are allowed to provide a catalog pre-configure object, in that it will automatically complete the application and optimal IT infrastructure resources. HP tries to provide the best services that emphasis on service, performance, security and good confidentiality.

\subsection{Andal PayMaster 2011}

PT Andal Software Sejahtera collaborates with Green View to develop cloud computing business model in the form of payroll calculation services cloud technology-based companies. This service provides data center with the content of it, Internet connectivity and VPN, DR / BC, operating systems and other supporting resources which are integrated and fully supported by the data security system that ensures the customers' data stored safely and always monitored well.

\section{COMPARISON}

Each service provider provides different services in order to attract the customers. This difference in services (business model) is the essence of research to compare to see the direction and business model used by the cloud provider in doing its business in developing countries in this case 
Indonesia. In making comparisons, the writer uses each service cloud computing provider that is previously mentioned based on the 8 (eight) business model classifications proposed by Victor et.al, as a parameter. The comparison has been summarized in the following table.

Tabel 1. Comparison of Cloud Computing Provider Business Model in Indonesia

\begin{tabular}{|l|l|}
\hline $\begin{array}{c}\text { Cloud Computing } \\
\text { Provider }\end{array}$ & \multicolumn{1}{c|}{ Business Model and Services } \\
\hline Telkom Indonesia & $\begin{array}{l}\text { Service Provider and Service } \\
\text { Orientation }\end{array}$ \\
\hline Indonesian Cloud & One Stop Resources and Services \\
\hline $\begin{array}{l}\text { PT Infinys Sistem } \\
\text { Indonesia }\end{array}$ & $\begin{array}{l}\text { Service Provider and Service } \\
\text { Orientation }\end{array}$ \\
\hline MorphLabs & $\begin{array}{l}\text { Service Provider and Service, } \\
\text { Orientation and Support and Service } \\
\text { Contract }\end{array}$ \\
\hline Huawei & $\begin{array}{l}\text { Support and Service Contract, } \\
\text { Service Provider and Service } \\
\text { Orientation }\end{array}$ \\
\hline Hewlett Packard & $\begin{array}{l}\text { Service Provider and Service } \\
\text { Orientation }\end{array}$ \\
\hline $\begin{array}{l}\text { PT Andal Software } \\
\text { Sejahtera }\end{array}$ & $\begin{array}{l}\text { Service Provider and Service } \\
\text { Orientation }\end{array}$ \\
\hline
\end{tabular}

See comparison in Table 1, Most of them use business model service provider and business model service orientation. Here, for the payment method of the types of business models above, it has been decided the rates based on infrastructure services rental costs and its complement. For example, Telkom Cloud determines the fees that are charged to users based on virtual private server rental service over a period of time that has been determined. The same case is also applied to some providers such as PT Infinys System Indonesia, MorphLabs, HP and PT Andal Software. Slightly different are Indonesian Cloud and Huawei. Here, the differences in business models are clearly visible from their operational goals. Indonesian Cloud is considered using a one-stop resource of business models and services because there is a collaboration between them and their consumers. It is where both of them have a mutually beneficial relationship each other.

For Huawei, the core of their business lies in the mobile service so that it is appropriate to support the business model and service contract. It is because they only have the right to access services during the subscription. Furthermore, Huawei Service also entered into Service Provider and Service Orientation a business model because in the future cloud services also support the IaaS and PaaS.

\section{CONCLUSIONS}

Based on the comparisons that have been done, this research can conclude that for developing countries, the business model which is appropriate or can approach the cloud computing service user needs is a business model that offers complete services such as business that was offered by Service Provider and Service Orientation business model. In the provider point of view, the fact is that a complete service can accommodate all consumer demands. Finally, the reason is because Indonesia as a developing country and also the government was poorly prepared in the provision of infrastructure which is qualified, so that it makes the cloud provider should provide service for consumers who need it.

\section{ACKNOWLEDGMENTS}

Thanks to Prof. Ir. Danny Manongga, M.Sc., Ph.D and Dr. Ir. Wiranto H. Utomo, M.Kom who was abundantly helpful and offered invaluable assistance, support and guidance to me during undergoing this research.

\section{REFERENCES}

[1] Hurwitz, J., Bloor, R., Kaufman, M., Halper, F. 2010. "Cloud Computing for Dummies", Wiley Publishing Inc, 111 River Street, Hoboken, NJ 07030-5774.

[2] Mell, P., and Grance, T. 2009. Draft NIST Working Definition of Cloud Computing.

[3] Wang, L., Von Laszewski, G., Kunze, M., Tao J. 2008. "Cloud Computing : a Perspective Study", Steinbutch Centre for Computing, Karlsruhe Institute of Technology Herman-von-Helmholtz-Platz 1, EggensteinLeopoldshaven, Germany.

[4] Boss, G., Malladi, P., Quan, S., Legregni, L., Hall, H. 2007. "Cloud Computing. Tehnical Report, IBM High Performance On Demand Solutions", 8 October 2007, Version 1.0

[5] Dinesh, C, G., Scholar. 2011. "Data Integrity and Dynamic Storage Way in Cloud Computing", Journal of Computer Applications (0975-8887) Volume 31 No 6 (Oktober 2011), Computer Science and Engineering, Mailam Engineering College, Mailam, Tamilnadu.

[6] Osterwalder, A. 2010. "Business Model Generation", Wiley.

[7] Huhtanen, K. 2010. "Cloud Computing Business Model".

[8] Chang, V., Wills, G., De Roure, D. 2010. "A Categorisation of Cloud Computing Business Models", School of Electronics and Computer Science, University of Southampton, Southampton SO17 1BJ.

[9] Brodkin, J. 2007. "IBM Unveils Cloud Computing Technologies for Internet-Scale Computing on The Way in Spring 2008 ", Network World, p10

[10] Papadopoulos, G. 2007. "My Advice is, If You Can't Take It Out, Don't Put It In", Financial Times, p2, London.

[11] Anderson, J. E., Wiles, F. A., Young, K. P., 2008. "The Impact of Cloud Computing on IS/IT Academics", Issues in Information Systems, Vol IX, No 1, p203-206.

[12] Bhadauria, R., Chaki, R., Chaki, N., Sanyal, S. "A Survey on Security Issues in Cloud Computing". School of Electronics and Communications Engineering, Vellore Institute of Technology, Vellore, India.

[13] Jensen, M., Schwenk, J., Gruschka, N., Iacon, L. L., 2009. "On Technical Security Issues in Cloud Computing". Proceeding of IEEE International Conference on Cloud Computing (CLOUD-II, 2009), pp. 109-116.

[14] Armbrust, M., Fox, A., Griffith, R., Joseph, A. D., Katz, R., 2009. "Above the Clouds : A Berkeley View of Cloud Computing", UC Berkeley Reliable Adaptive Distributed System Laboratory White Paper. 
[15] Buyya, R., Broberg, J., Goscinski, A., 2011. "Cloud Computing Principles and Paradigms", A John Wiley \& Sons Inc, Hoboken, New Jersey.

[16] Wang, L., Von Laszewski, G., Kunze, M., Tao, J. 2008. "Cloud Computing : A Perspective Study", Steinbuch Centre for Computing, Karlsruhe Institute of Technology Herman-Von-Helmholtz-Platz 1, EggensteinLeopoldshafen, Germany.

[17] Papazoglou, M. P., Van den Heuvel, W. J., 2007. "Service Oriented Architecture : Approaches,
Technologies and Research issues", The VLDB Journal, 16: 389-415.

[18] Goldberg, R. P., 1974. "Survey of Virtual Machine Research”, IEEE Computer, 7(6):34-45.

[19] International Business Machines Corp. 2006. "An Architectural Blueprint for Autonomic Computing", White Paper Fourth Edition.

[20] Huebscher, M. C., McCann, J. A., 2008. "A Survey of Autonomic Computing Degrees, Models, and Applcations ”, ACM Computing Surveys, 40:1-28 